\title{
Nudging in Public Policy: Application, Opportunities and Challenges
}

One of the most discussed contemporary ideas in policy making is Richard Thaler and Cass Sunstein's proposal to influence people's choices without coercing them by improving the "architecture" of their choices. Many governments have implemented behaviourally informed policies, focusing on "nudges" - interventions that preserve freedom of choice, but that also steer people in certain directions. In many countries, behavioural science has become fundamental to policy choices in areas that include consumer protection, health care, environmental protection, tax policy, poverty, retirement and much more. The European Commission has been a front-runner in applying behavioural insights to its policy making over the past decade. What are the opportunities and challenges presented by the application of behavioural insights to policy at a supranational regulating body? What does it mean to apply behavioural insights to policy making? When it comes to consumer legislation, could behavioural economics be used as a tool for bringing the EU closer to its citizens? What do citizens actually think about behaviourally informed policies? Is this method of influencing choices ethically acceptable? Finally, should the findings of behavioural economics be alarming to normative economists, in that they threaten the grounds upon which economists evaluate alternatives? If preferences, especially as shown in the choices people actually make, do not reliably indicate what is good for individuals, then normative economics requires a drastic rethinking.

Behavioral Economics and Public Opinion

Cass R. Sunstein, Harvard University, Cambridge, MA, USA.

Lucia A. Reisch, Copenhagen Business School, Denmark.

How Can Behavioural Insights Be Used to Improve EU Policy?

Xavier Troussard, European Commission, Brussels, Belgium.

René van Bavel, European Commission, Seville, Spain.

Using Behavioural Economics For Rather than Against Consumers - A Practitioner's Perspective

Monique Goyens, European Consumer Organisation (BEUC), Brussels, Belgium.

Nudging and Other Ways of Steering Choices

Daniel M. Hausman, University of Wisconsin-Madison, USA. 